\title{
A Study for immerge VR Applied in RC Building Earthquake Damage Assessment
}

\author{
Ren-Jwo Tsay \\ Department of Civil Engineering, Vanung University \\ Chungli District, Towyang City, Taiwan \\ trj@vnu.edu.wt
}

\begin{abstract}
The damage to the building structure after damage caused by external forces will be used for subsequent treatment such as repair, reinforcement or demolition. However, the current evaluation methods mostly require professionals' experience and academic background, which cannot be widely popularized. Therefore, general personnel such as users or insurance claims personnel must conduct preliminary investigations. However, if the form of structural damage is displayed in unit parts, there will be a huge gap with real structure damage conditions after hazard. If we can build a three-dimensional model of analysis and theoretical structure damage and user can enter the virtual space for observation training, it will effectively improve the accuracy of future practical application.

For actual structural damage behavior, researchers used experiments in the laboratory tests, the structure analysis by software such as SAP program provide function of pushover to analysis the structure behavior subjected to lateral force, which we can evaluate the behavior of the structure from the original state to the destruction. This paper we used the SAP pushover function to analyze the failure mode of the structure at different stages. The failure mode of the system is evaluated by the stress analysis then we setup SketchUp model to simulate the damage behavior in different stages. Then import the 3D model to cloud VR system users can view the models in 3D immerge environment. To establish immerge VR structural damage assessment training system. Users can actually observe structural damage in a VR not only to protect users from the risk of entering the actual building to define the damage it can also improve the accuracy of future practice judgments.
\end{abstract}

Keywords: Immerge VR, structure damage simulation, SAP pushover, SketchUp

\section{Introduction}

For the safety assessment after the structure damaged by earthquake or hazard force, it is often necessary to make an empirical assessment from the damage conditions by a professional engineers or architects. However, in practice, there are not enough engineers so the initial assessment must by non-professionals people to define the building damage condition. Many countries are actively establishing post-earthquake damage evaluation criteria, but the implementation of most systems is troubled by the different evaluation standards of non-professional evaluators. Therefore, if we can establish a visual standard evaluation system so we can improve the building damage level estimate quality. The researchers developed relation research as follow. Gambarotta et al. [1][2] developed numerical models to simulation the brick wall applied by cycle horizontal force. Maidiawati et al. [3] used laboratory test and numerical analysis result to find the RC infill brick wall damage response in earthquake. In order to define the structure collapse pattern Abid et al. [4] develop an assessment and appraisal technical so users can get the building damage conditions.

However the former studies defined the assessment level must define by real side conditions so it is difficult to train new assessors to get a real situation so they can clear understood the building damage level. In this paper we developed a 3D VR building damage model first we defined the building hazard by numerical method then setup different step damage of building so users can get in immerge VR environment to get 3D concept for building hazard.

\section{Structure Failure Mode Establishment and Failure Model Establishment VR Application 2-1. Structural Damage Analysis}

2-1-1. Plastic hinge for beam column system

(a) $\mathrm{RC}$ beam column plastic hinge 
For RC column and beam plastic hinge analysis we can applied the yield stress to tension and compression steel to found the plastic moment as Eq. 1 shown.

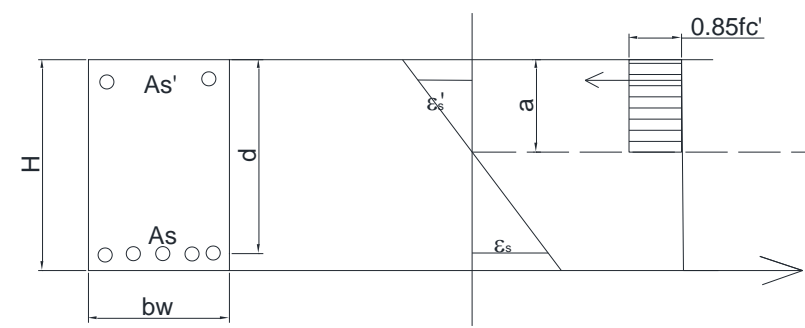

Fig 1. RC section bending stress

RC plastic moment $M_{p}$

$$
M_{p}=M_{c}+M_{t}=\left(A_{s}-A_{s}^{\prime}\right) f_{y}(d-a / 2)+A_{s}^{\prime} f_{y}\left(d-d^{\prime}\right)
$$

Where

$A_{s}, A_{s}{ }^{\prime}:$ tension and compression steel area

$d$ :effective depth

$a$ : concrete compression stress distribution depth

2-1-2. Wall damage analysis

2-1-3. Brick wall damage analysis

(b-1) brick wall shear resistance strength

For brick shear wall resistance capacity Dr Chang [7] applied diagonal strut model theory and laboratory test to get the shear wall retain capacity as Fig.2. He also suggest the brick wall shear limit stress as Eq.2

$$
\tau_{\text {brick }}=0.33 \mathrm{MPa}=3.3 \mathrm{~kg} / \mathrm{cm}^{2} \text {. }
$$

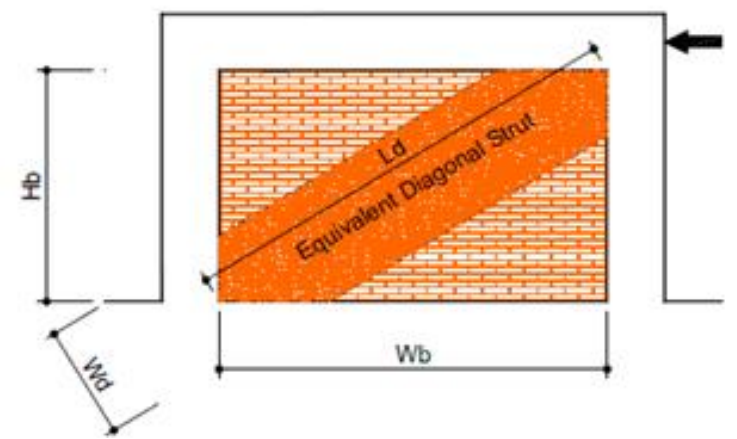

Fig 2. Brick wall Equivalent Diagonal Strut model [7]

The equivalent diagonal strut model width was as Eq. 3 shown.

$$
W_{d}=0.33 L_{d}
$$




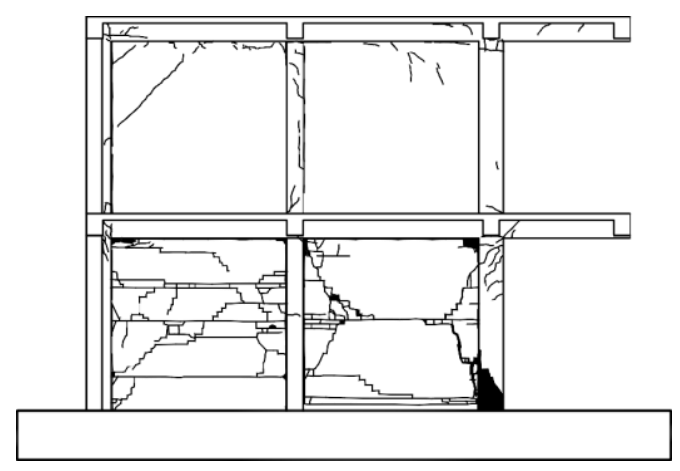

Fig 2. Brick wall damage laboratory test results [7]

(b-2)RC shear wall resistance strength

From ACI 318-11the RC shear wall can be got by concrete and shear reinforced steel as Eq.4 shown.

$$
V_{n}=V_{c}+V_{s}
$$

Concrete shear strength

$$
\begin{aligned}
& \text { For non-axis concrete } V_{c}=0.53 \sqrt{f_{c}^{\prime}} b_{w} d \\
& \text { For axis concrete } V_{c}=0.53\left(1+\frac{N_{u}}{140 A_{g}}\right) \sqrt{f_{c}^{\prime}} b_{w} d
\end{aligned}
$$

Shear steel strength $V_{s}=\frac{A_{v} f_{y} d}{s}$

Where

$f_{c}^{\prime}$ : concrete strength

$b_{w}:$ section width

$d$ : effective depth

$f_{y}:$ steel yield stress

$s$ : shear wall steel spacing

$A_{v}:$ shear steel section area

So we can get the non-axis force $\mathrm{RC}$ wall shear strength as Eq. 8 .

$$
\tau_{s w}=\left(V_{c}+V_{s}\right) / b_{w} d=0.53 \sqrt{f_{c}^{\prime}}+\frac{A_{v} f_{y}}{b_{w} s}
$$

Then we defined the wall damage level by wall stress analysis results as table 1 .

Table1. RC and Brick wall damage level definition

\begin{tabular}{|l|l|l|}
\hline Damage level & RC wall & Brick wall \\
\hline I & $0<\tau \leq \frac{1}{4} \tau_{s w}$ & $0<\tau \leq 0.825 \mathrm{~kg} / \mathrm{cm}^{2}$ \\
\hline II & $\frac{1}{4} \tau_{s w}<\tau \leq \frac{1}{2} \tau_{s w}$ & $0.825 \mathrm{~kg} / \mathrm{cm}^{2}<\tau \leq 1.75 \mathrm{~kg}^{2} \mathrm{~cm}^{2}$ \\
\hline III & $\frac{1}{2} \tau_{s w}<\tau \leq \frac{3}{4} \tau_{s w}$ & $1.75 \mathrm{~kg}^{2} \mathrm{~cm}^{2}<\tau \leq 2.475 \mathrm{~kg}^{2} \mathrm{~cm}^{2}$ \\
\hline
\end{tabular}




\begin{tabular}{|c|c|c|}
\hline IV & $\frac{3}{4} \tau_{s w}<\tau \leq \tau_{s w}$ & $2.475 \mathrm{~kg} / \mathrm{cm}^{2}<\tau \leq 3.3 \mathrm{~kg} / \mathrm{cm}^{2}$ \\
\hline $\mathrm{V}$ & $3.3 \mathrm{~kg} / \mathrm{cm}^{2}<\tau$ & $3.3 \mathrm{~kg} / \mathrm{cm}^{2}<\tau$ \\
\hline
\end{tabular}

\section{2-2.structure damage 3D model setup}

In order to define the structure damage levels many countries provide different define method. Ministry of the Interior construction agency of Taiwan developed visualization criteria to found the structure damage level as Fig. 6 to Fig. 8 shown. So evaluator can compare the actual filed condition to define the building safety state.

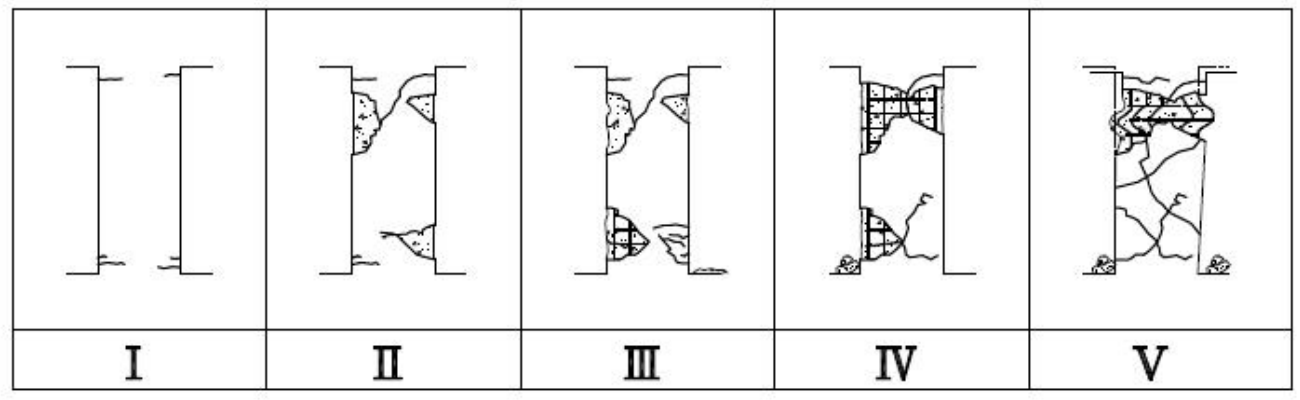

Fig. 6 Column damage level definition [10]

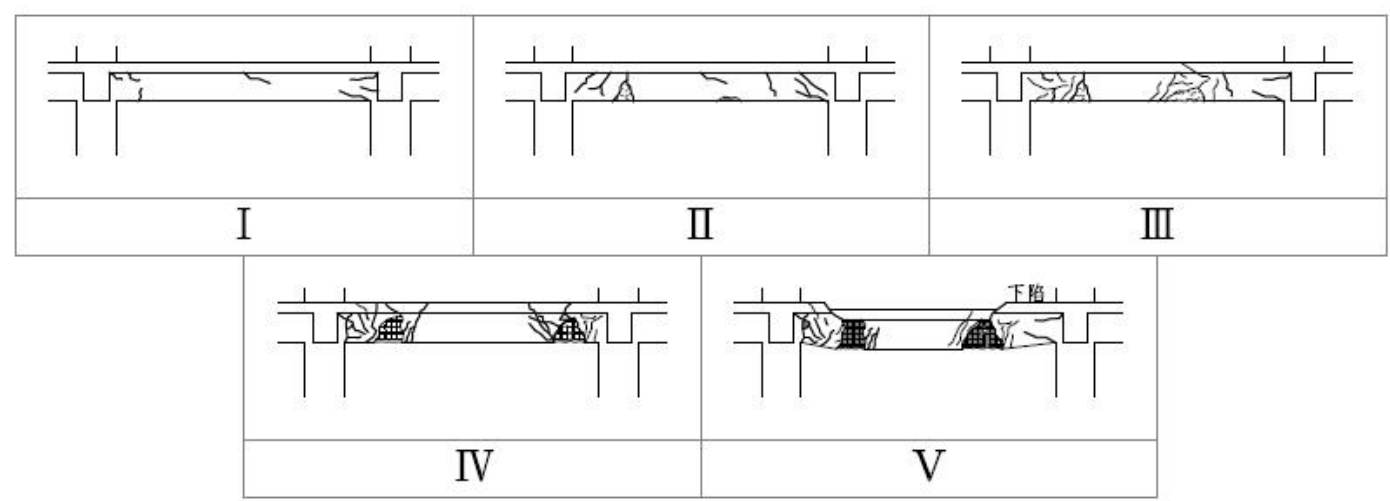

Fig. 7 Beam damage level definition [10]

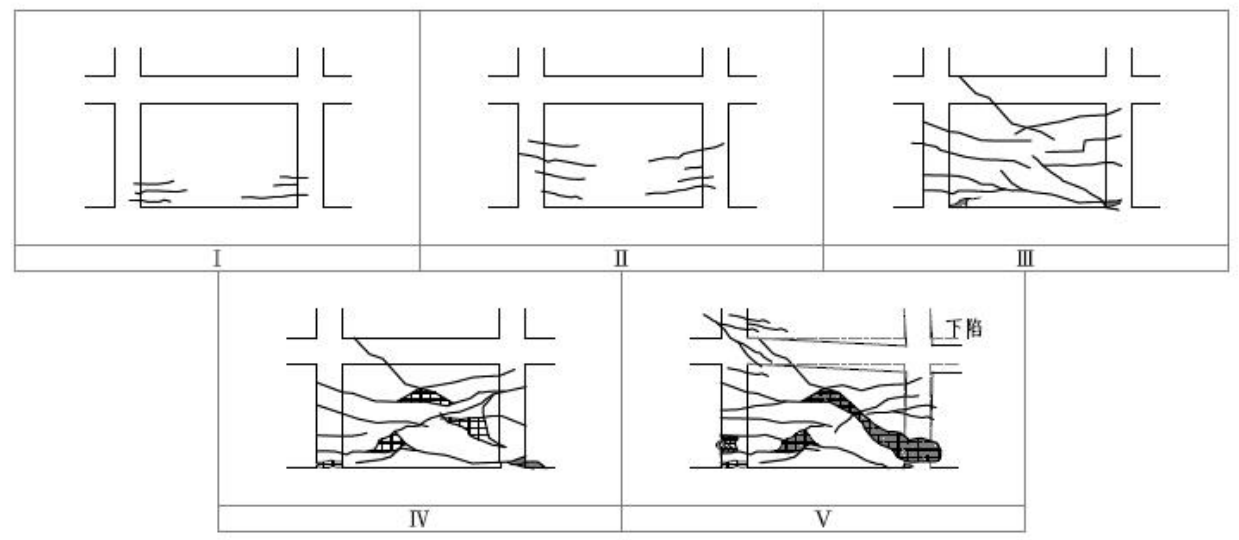

Fig. 8 RC Shear wall damage level definition [10] 


\section{2-3. Pushover structure damage analysis}

The numerical pushover method defined the structure behavior side force deflection response from initial to damage by step increase force loading. This method can be got in different commercial building analysis program, such as SAP and ETABS program. Users can applied a increase steady static force in building so to get the whole building response. In Fig. 9 new can found the damage moment-deflection degree curve condition in different step. The damage results to whole building beam column element plastic hinge conditions could be found as Fig. 10 shown

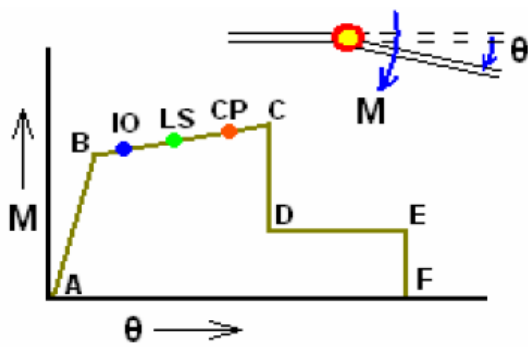

Fig. 9 The pushover curve response [8]

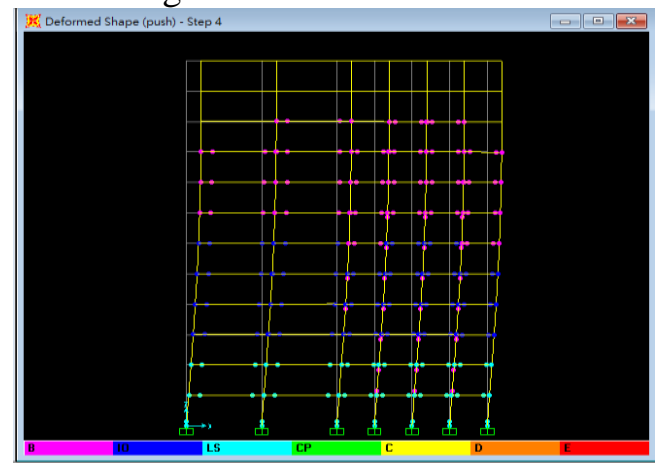

Fig. 10. SAP pushover analysis results sample

\section{2-4. 3D Damage Model Definition}

From structure damage level definition, we setup different structure element damage 3D model for different level as follow. From SAP pushover and wall stress analysis found the building damage conditions in different step, so we can create simulation building damage by $3 \mathrm{D}$ model for different structure systems. We defined the damage of column, RC beam, RC shear wall and brick wall damage models as Fig. 12 to Fig. 14.

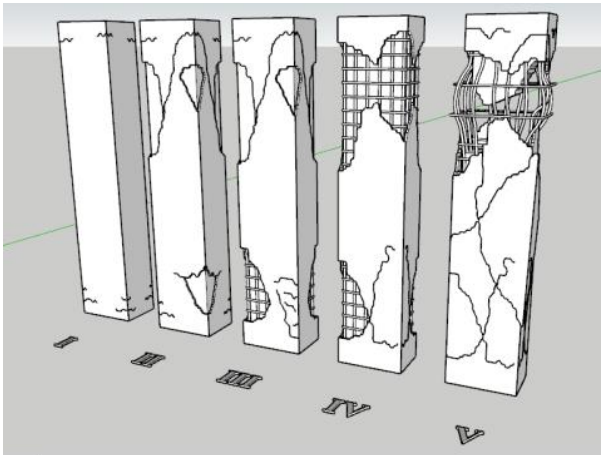

Fig.11 RC column damage degree definition

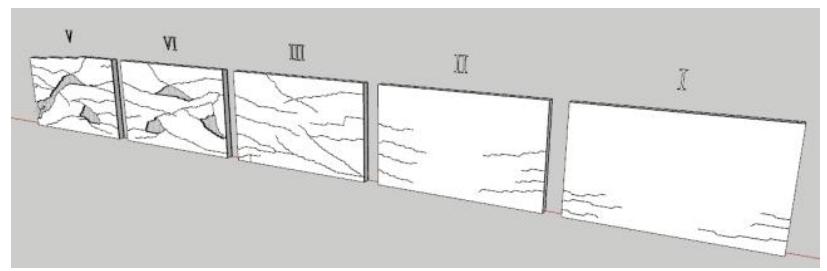

Fig. 13 RC Shear wall damage degree definition

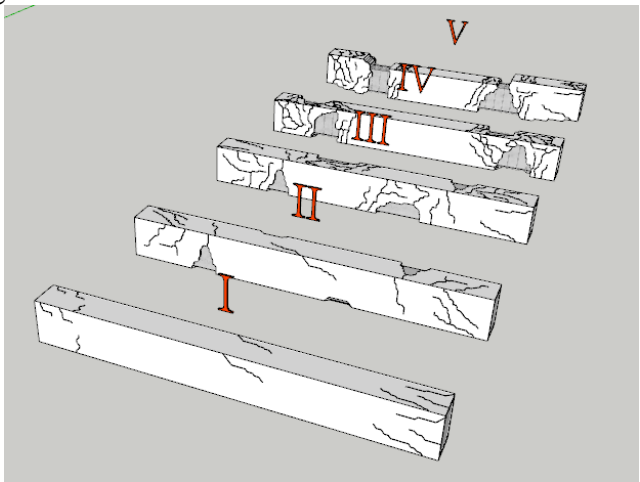

Fig.12 RC beam damage degree definition

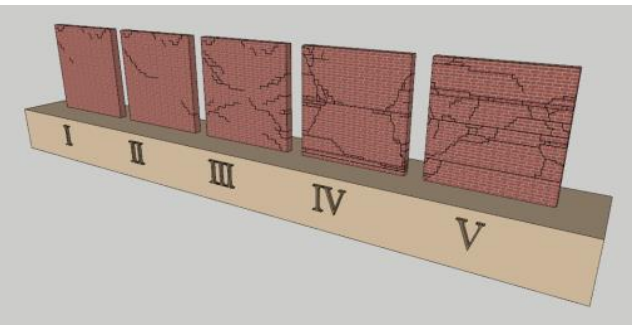

Fig.14 Brick wall damage degree definition 


\section{2-5. Immerge VR display}

VR observation methods can be divided into two types: guided and immersed. The guided is the use of setting key screens in the VR environment to create animations by VR software. The observation path and angle cannot be determined by the users. Another immersive method places the observer in the virtual environment of the observation environment. Users can choice the view point and angle to observe the detail of structure behavior. The comparison for guild and immerge VR was shown in Table1.

The Vive system can get the function for dynamic view function, but specific equipment and software were required. Kubity (as Fig 15 shown) was a web platform which can export 3D model such as SketchUp and Revit software. Users can use portable device such as cell phone or tablets to view the 3D model in different point and angle.

Table 2. The comparison for guild and immerge VR

\begin{tabular}{|c|c|c|}
\hline & Guild VR & Immerge VR \\
\hline $\begin{array}{l}\text { Production } \\
\text { method }\end{array}$ & $\begin{array}{ll}\text { 1. } & \text { Build a 3D model } \\
\text { 2. } & \text { Set the key screen } \\
\text { 3. } & \text { Perform guided animation production } \\
\text { 4. } & \text { Export animation }\end{array}$ & $\begin{array}{l}\text { 1. Create a 3D model } \\
\text { 2. Export the model to the cloud } \\
\text { 3. Observe the } 360 \text {-degree space view with a } \\
\text { portable device }\end{array}$ \\
\hline Observe method & Observe with a fixed path on the screen & $\begin{array}{l}\text { Users can choice observation path and angle in } \\
\text { 3D immerge environment }\end{array}$ \\
\hline
\end{tabular}

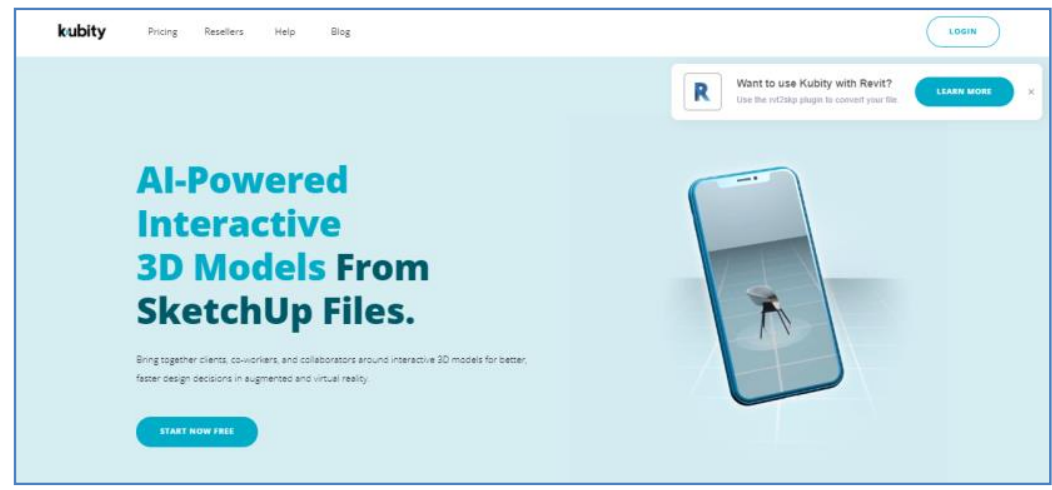

Fig. 15 Kubity official web [12]

\section{Building Damage VR Simulation Application}

\section{3-1. 30 year brick filled RC city hall damage analysis}

In this study we applied former method to define a 30 year 3F brick infill RC frame old city hall damage conditions. The plan and elevation map for building were shown as Fig. 15. Applied the model to SAP pushover analysis we can get the response curve as Fig. 16. From the analysis results for each step plastic hinges development we can build the building damage Sketchup model as Fig. 17. After upload the 3D model to Kubity we can get VR result as Fig. 17 shown. 

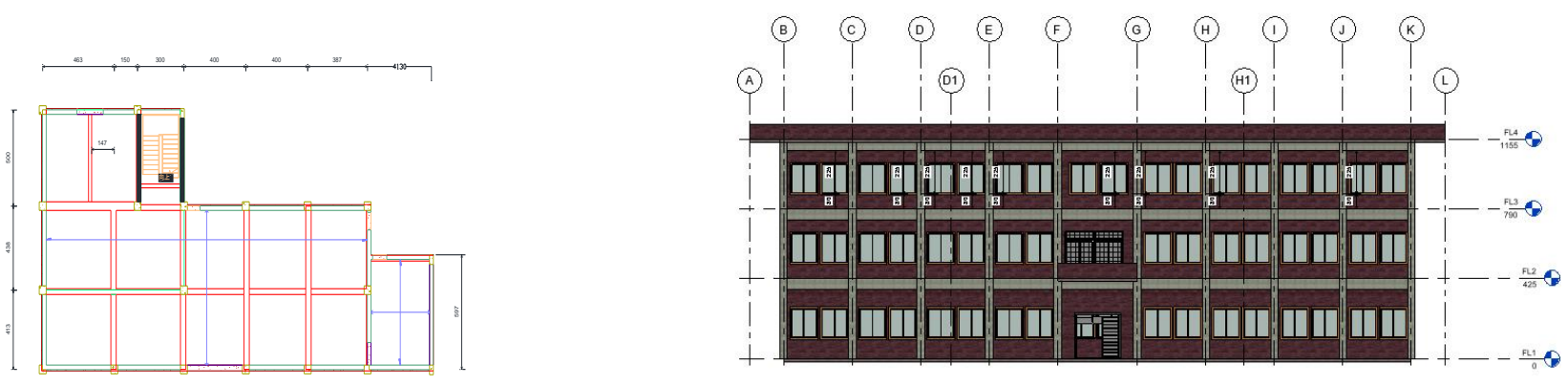

Fig. 15 brick filled RC city hall floor plan and elevation map
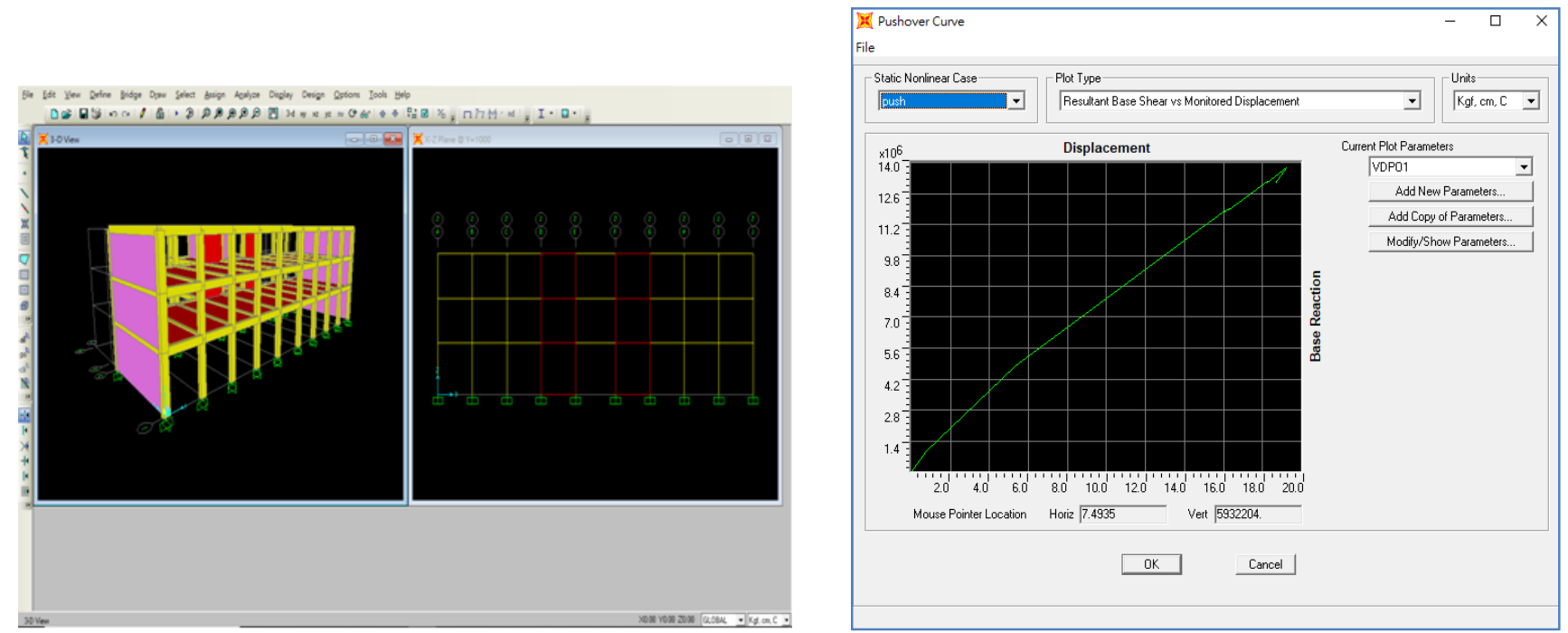

Fig. 16 SAP numerical model and pushover result for brick filled RC city hall
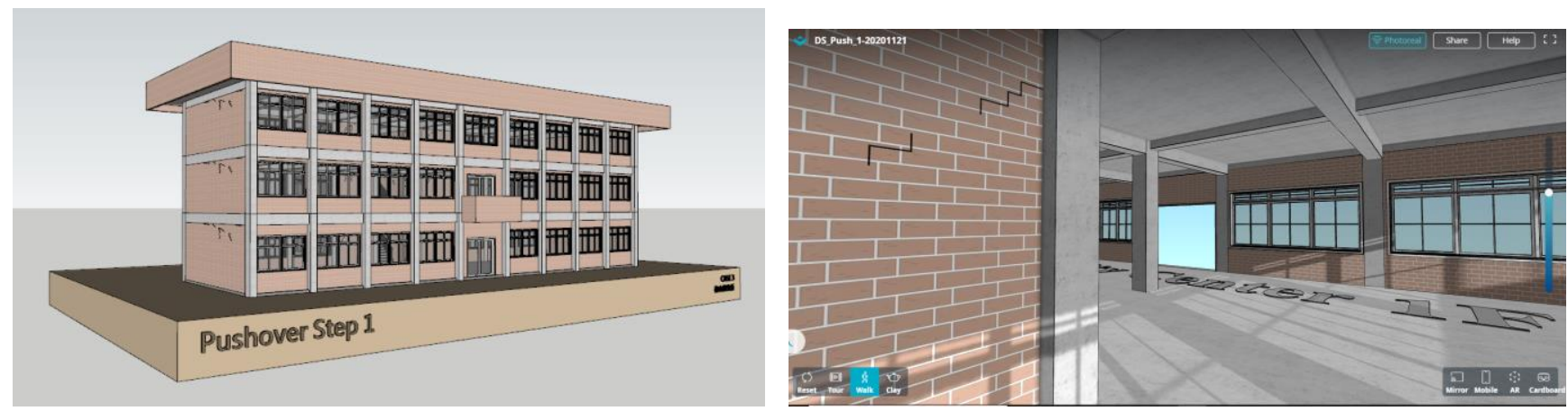

Fig. 17 Brick filled RC city hall damage simulation SketchUp and internal VR model 


\section{Conclusion}

Form above discussion we can get the conclusion as follow.

1. Use SAP lateral push analysis to establish building failure mode criteria and combine the VR function to establish an immersive environment so that users can choose to observe the environment or enter each member to observe the behavior mode of structural damage.

2. This study developed a simulation of actual structural failure and can establish a basis for failure assessment criteria.

3. The analysis model developed in this article can not only provide structural damage assessment during the design process, but also serve as an application for structural earthquake damage related education and training.

\section{References}

[1] I. Gambarotta, and S. Lagomarsino, "Damage model for the seismic response of masonry shear wall. Part I: The mortar joint model and its applications," Earthquake Engineering and structural Dynamic, vol. 26, pp.423-439,1997

[2] I. Gambarotta, and S. Lagomarsino, S., "Damage model for the seismic response of masonry shear wall. Part II: The continuum model and its applications," Earthquake Engineering and structural Dynamic, vol. 26, pp.441-462,1997

[3] Maidiawati, Y. Sanada, D. Konishi and J. Tanjug, "Seismic Performance of Nonstructural Brick Walls Used in Indonesian R/C Buildings," Journal of Asian Architecture and Building Engineering, vol.. 10, No. 1, pp. 203-210, 2011, [Online]. Available:

https://www.researchgate.net/publication/285940792_Seismic_Performance_of_Nonstructural_Brick_Walls_Used_in _Indonesian_RC_Buildings

[4] Abid Abu-Tair, Eng. Gavin Wilde, Maher Amro, Munther Ibrahim, "Urban Search and Rescue and Rapid Field Assessment of Damaged and Collapsed Building Structure.”, International Journal of Civil, Environmental, Structural, Construction and Architectural Engineering, 2015, [Online]. Available: http://dsr.ppu.edu/sites/default/files/conference/abstracts/Rapid\%20Field\%20Assessment.pdf

[5] FEMA, "Post-disaster Building Safety Evaluation Guidance 2019”, [Online]. Available:, https://www.fema.gov/media-library-data/1582075507794-f81a6bc7e3214ae9b2988687fce3d2cb/FEMA_P2055_Post-disasterBuildingSafetyEvaluation_508.pdf

[6] ATC-20-1, "Field Manual: Field Manual: Postearthquake Safety Evaluation of Building," Applied Technology Council, 2005, [Online]. Available:, https://www.atcouncil.org/45-downloadable/downloads/107-atc-20-download

[7] I. S. Chang , "Seismic Evaluation of RC Buildings Infilled with Brick Walls" , National Cheng Kung University PhD. Dissertation, 2003

[8] R. Leslie , "The Pushover Analysis , explained in its Simplicity" , [Online]. Available: , https://www.researchgate.net/publication/323607343_The_Pushover_Analysis_in_its_Simplicity

[9] T. Fabio and P. V. Artur, "Field Manual for post-earthquake damage and safety assessment and short term countermeasures," European Commission Joint Research Centre Institute for the Protection and Security of the Citizen, 2007.

[10] Ministry of the Interior Construction Agency, Taiwan, "Emergency assessment methods for dangerous buildings after disasters", 2009

[11] S. Anagnostopoulosa,and M. Moretti ,"Post-earthquake emergency assessment of building damage, safety and usability_Part 1: Technical issues, "Soil Dynamics and Earthquake Engineering, vol. 28, No. 3, pp.223-232, 2008

[12] Kubity, [Online]. Available:, https://pro.kubity.com/ 